\title{
Article
}

\section{Characteristic of silicon doped diamond like carbon thin films on surface properties and human serum albumin adsorption}

Ahmed, Mukhtar, Byrne, John and Ahmed, Waqar

Available at http://clok.uclan.ac.uk/11933/

Ahmed, Mukhtar, Byrne, John and Ahmed, Waqar ORCID: 0000-0003-41525172 (2015) Characteristic of silicon doped diamond like carbon thin films on surface properties and human serum albumin adsorption. Diamond and Related Materials, 55 . pp. 108-116.

It is advisable to refer to the publisher's version if you intend to cite from the work. http://dx.doi.org/10.1016/j.diamond.2015.03.016

For more information about UCLan's research in this area go to http://www.uclan.ac.uk/researchgroups/ and search for <name of research Group>.

For information about Research generally at UCLan please go to http://www.uclan.ac.uk/research/

All outputs in CLoK are protected by Intellectual Property Rights law, including Copyright law. Copyright, IPR and Moral Rights for the works on this site are retained by the individual authors and/or other copyright owners. Terms and conditions for use of this material are defined in the policies page. 


\title{
Characteristic of Silicon Doped Diamond Like Carbon thin films on surface properties and Human Serum Albumin Adsorption
}

\author{
Mukhtar H. Ahmed ${ }^{1 *}$ John A. Byrne ${ }^{1}$ and Waqar Ahmed ${ }^{2}$ \\ 1- Nanotechnology Integrated Bio-Engineering Centre, University of Ulster, \\ Shore Road, BT37 0QB, Belfast, UK \\ 2- Institute of Nanotechnology \& Bioengineering, School of Medicine and \\ Dentistry, University of Central Lancashire, Preston, PR1 2HE, UK \\ *Corresponding author email: ahmed-m@email.ulster.ac.uk
}

\begin{abstract}
Keywords: Human Serum Albumin, Diamond Like Carbon, Si-DLC, Raman spectroscopy, Atomic force microscopy
\end{abstract}

\begin{abstract}
Diamond-like carbon (DLC) coatings are useful for creating biocompatible surfaces for medical implants. DLC and silicon doped DLC have been synthesised using plasma enhanced chemical vapour deposition (PECVD). The effects of surface morphology on the interaction of human serum albumin (HSA) with doped and undoped DLC films have been investigated using a range of surface analysis techniques using Raman spectroscopy and atomic force microscopy (AFM). Raman spectra of doped DLC show silicon doped DLC reduces the growth range of $\mathrm{I}_{\mathrm{D}} / \mathrm{I}_{\mathrm{G}}$ ratio, with significant red-shift of $\mathrm{G}$ peak position. Following exposure to protein, for undoped DLC the peaks at $1664 \mathrm{~cm}^{-1}$ and around 1241 $\mathrm{cm}^{-1}$ can be attributed to amide I and III, respectively, with an increase in the surface morphology of the surfaces giving some indication of the protein structure on the surfaces. Results indicate that HSA exhibit the majority of $\beta$-sheet during the adsorption on the surfaces. The results showed that the silicon incorporation DLC tends to increase of surface roughness and the adsorbed level of HSA is higher with higher levels of silicon doping of the DLC. Therefore, doping DLC may provide a method of controlling the adsorption of protein.
\end{abstract}




\section{Introduction}

Interest in the field of biomaterials has increased over the last three decades due to their importance in repair and replacement of diseased or damaged tissues in the body. The implantation of biomaterials into the human body allows it restructure function and hence to enhance the quality of life.

Protein interaction is central to many biological processes including the interaction of cells with the surfaces of biomaterials. The adsorption of proteins to the surface of biomaterial is of great importance because of its governing role in determining cellular responses to implanted materials and substrates for tissue engineering and regenerative medicine [1]. The understandings of the fundamental factors that determine protein adsorption are imperative to improve our ability to design biocompatible materials and biotechnological devices.

Due to its unique combination of desirable properties including chemical inertness, high density, heamocompatibility and poor coefficient of friction [2], diamond like carbon (DLC) is an attractive biomaterial for coating human implantable devices $[3,4]$, such as rotary blood pumps [5] mechanical heart valves [6], coronary artery stents [7], hip and knee replacements [8]. DLC films have shown excellent hemocompatibility, resulting in a reduction of thrombosis formation and cytotoxic reactions in vitro and in vivo as observed by the normal cell growth on DLC surfaces [9], which has been regarded as important advances in the field of biomedical devices and implants [2].

The chemical and physical properties of the surface such as the elemental composition, functional groups and surface energy are very important and play a role in enhancing or decreasing the adsorption of proteins or biological compounds of the implant. Thus, to enhance the biocompatibility of DLC, doping has been investigated involving the incorporation of third element such as nitrogen [10], fluorine [11], silicon [12] and titanium [13].

It has been reported that silicon incorporation into DLC tended to improve the chemical stability and wear resistance of the DLC films [14]. Si-DLC overcomes some of the drawbacks mentioned, including low intrinsic compressive stress, good adhesion, and mechanical resistance [15], which are beneficial for biomedical applications. Improvements in blood compatibility with silicon doped DLC film where a decrease of inflammatory reactions was observed compared to undoped DLC [16]. 
To improve understanding and predict protein-surface interaction behaviour, DLC and Si-DLC have been studied using human serum albumin (HSA). This study aims to illustrate the conformational changes in proteins upon attachment to surfaces, and adsorption on the surfaces for lengthy periods, in order to obtain a better understanding of the dynamic phenomena in protein adsorption.

In this contribution, we explore the coating of silicon wafer substrates with DLC and silicon doped DLC thin films using plasma enhanced chemical vapour deposition (PECVD). The adsorption process of Human serum albumin (HSA) is investigated, since its adsorption onto surgical instruments and medical devices is likely to dominate in vivo due to its abundance in the human serum.

\section{Experimental}

\subsection{Film Preparation and modification}

DLC and Si-DLC were deposited on silicon wafer by the radio frequency (RF) 13.56 MHz PECVD using a Diavac model 320PA (ACM Ltd.), with negative electrode selfbias voltages set at 400 Volt. Before deposition of the films, substrates of silicon wafers $(1.0 \times 1.0) \mathrm{cm}^{2}$ were cleaned using an ultrasonic bath in acetone and isopropanol (1:1) for 5 minute followed by washing with distilled water and then dried using nitrogen gas.

The experimental equipment had been described in detail previously [17]. The cleaned substrates were placed in the deposition chamber on top of a water-cooled electrode driven by an RF power supply. When the chamber pressure reached $\sim 5 \times 10^{-6}$ Torr, the glow discharge argon plasma $\left(60 \mathrm{~cm}^{3} / \mathrm{min}\right)$ was used to clean substrate and make the surface rough and to deposit evaporated coating material. The films were prepared under the following conditions: Argon was used as a carrier gas, and $\mathrm{C}_{2} \mathrm{H}_{2}$ with tetramethylsilane (TMS) $\left(\mathrm{Si}\left(\mathrm{CH}_{3}\right)_{4}\right.$ [99.8\% Sigma-Aldrich] were used as reactant gas. The $\left(\mathrm{Ar}: \mathrm{C}_{2} \mathrm{H}_{2}\right)$ flow ratio was fixed at $(10: 20)$ standard cubic centimetre per minute (sccm), and the deposition time was fixed for 5 minute. In the case of silicon doped DLC, the various doping concentrations of silicon were achieved using TMS. Detailed parameters are given in Table 1. 
Table 1: Conditions of the DLC and Si-DLC films deposition process

\begin{tabular}{|c|c|c|c|c|}
\hline \multirow{2}{*}{ Parameters } & \multicolumn{4}{|c|}{ Samples } \\
\cline { 2 - 5 } & DLC & S-1 & S-2 & S-3 \\
\hline rf. Power (Watt) & 102 & 107 & 119 & 128 \\
\hline Ar: $\mathrm{C}_{2} \mathrm{H}_{2}$ ratio (sccm) & $10: 20$ & $10: 20$ & $10: 20$ & $10: 20$ \\
\hline $\begin{array}{c}\text { Pressure in Process x10- } \\
2\end{array}$ & 0.69 & 0.83 & 1.17 & 1.68 \\
\hline TMS florr) & 0 & 2 & 5 & 10 \\
\hline Film thickness (nm) & $168 \pm 12$ & $182 \pm 15$ & $202 \pm 13$ & $239 \pm 16$ \\
\hline (ID $/ \mathrm{I}_{\mathrm{G}}$ ) ratio & 0.60 & 0.52 & 0.45 & 0.39 \\
\hline Water contact angle $(\theta)$ & $79.3^{\circ} \pm 1.4$ & $80.1^{\circ} \pm 1.8$ & $82.7^{\circ} \pm 1.3$ & $86.4^{\circ} \pm 1.7$ \\
\hline
\end{tabular}

(rf): radio frequency, (W): watt, Bias voltage: 400 volt, deposition time: 5 minute, (TMS): Tetramethylsilane, (sccm): standard centimetre cube per minute, nm: nanometre, Initial chamber pressure: $\sim 5 \times 10^{-6}$ Torr, $( \pm)$ is SD for $n=(5-7)$ samples. $\left(\mathrm{I}_{\mathrm{D}} / \mathrm{I}_{\mathrm{G}}\right)$ : is the intensity ratio between disorder induced (D) and graphite (G) band.

\subsection{Adsorption studies}

$0.1 \mathrm{mg} / \mathrm{ml}$ of HSA (from Sigma-Aldrich) solution was prepared in physiologic buffer solution using $0.01 \mathrm{M}$ pH 7.4 of Phosphate Buffer Saline (PBS tablets from SigmaAldrich). The clean and dry coated samples were immersed in $10 \mathrm{ml}$ of above solution in separate jar. The component was incubated for 30 minute with the adjusted temperature of $(37 \pm 1)^{\circ} \mathrm{C}$. At the end of the adsorption period, the samples were rinsed and washed using distilled water and then dried.

\subsection{Surface characterisation}

Stylus profilometry was used to determine the film thickness (Dektak 8 Advanced Stylus Profiler Veeco Instruments Inc., USA).

XPS measurements were taken using a KRATOS XSAM 800 equipped with an energy analyser (15 keV and $5 \mathrm{~mA}$.) with a monochromatic Aluminium K-alpha X-ray source at $\mathrm{hv}=1486 \mathrm{eV}$. The operating pressure in the analysis chamber was kept around $\sim 8.6 \times$ 10-10 bar. All spectra were referenced by setting the $\mathrm{C} 1 \mathrm{~s}$ peak to $285.0 \mathrm{eV}$ to compensate for residual charging effects.

Raman Spectroscopy was carried out on all samples before and after adhesion of HSA, by ISA lab-ram model system using an Argon laser beam 50 mW $633 \mathrm{~nm}$ laser diode for excitation. The following parameters were used: confocal aperture $200 \mu \mathrm{m}$, spectral 
resolution $5 \mathrm{~cm}^{-1}$. A 100× objective was employed with typical acquisition times of 7 seconds and repeated 10 times. This process was repeated at five different spots across the samples prepared before and after the adhesion process. Prior to data acquisition the spectrometer was calibrated using the zero order diffraction peak and first order peak from a silicon phonon mode (at $520 \mathrm{~cm}^{-1}$ ) from a silicon wafer sample.

The surface morphology of the synthesised films before and after adsorbed of HSA was obtained and analysed by atomic force microscopy (AFM), using a Dimension TM 3100 (Veeco Metrology group). Imaging was performed under ambient conditions at room temperature using a sharp silicon probes $(\mathrm{R}=20 \mathrm{~nm})$, attached to a low stress soft silicon nitride cantilever with no reflecting coating on its back side [spring constant $\sim 0.033 \mathrm{~N} / \mathrm{m}$ and resonant frequency around $15 \mathrm{kHz}$ with the applied force of $500 \mathrm{mV}$ ]. The AFM exhibited a maximum scan area of $10 \mu \mathrm{m} \times 10 \mu \mathrm{m}$ and a vertical range of $3 \mu \mathrm{m}$ and was calibrated using calibration gratings purchased from Micro Masch. A root mean square surface roughness (rms) was derived directly from the AFM height images.

The contact angle of water was measured in atmospheric conditions at room temperature with a contact angle meter (CAM 200 optical contact angle system, KSV instruments LTD, Finland). A drop of $5 \mu \mathrm{L}$ of double distilled water was generated with a micrometric syringe and was deposited on the substrate surfaces. The contact angle was read at five different places on each sample surface. The average contact angle for each film was determined along with the standard error.

\section{Results and Discussion}

The film thickness of DLC was $168 \mathrm{~nm}$, with the addition of silicon to the films causing an increase in the film thickness, i.e. 182, 202 and $239 \mathrm{~nm}$ for TMS flow rates of 2, 5 and 10 sccm respectively (Table 1). Thus the contents of silicon increased with film thickness possible due to the fact that silicon atom has a larger radius than carbon [18]. In contrast, the $\mathrm{Si}-\mathrm{C}$ bond length $(1.89 \AA)$ is more than $20 \%$ longer than that in C-C bond length (1.54 A). These results are similar to those observed in our previous study [17].

\section{1 surface contact angle}

The contact angle is essential to understand the wetting properties of the surfaces. The contact angle value of the DLC and Si- DLC films are shown in Table 1. DLC film tends 
to be a mild hydrophobic surface with a water contact angle of approximately $79.3^{\circ}$. This result is consistent with those obtained in our earlier studies [10]. The silicon incorporated DLC films tends to be hydrophobic surfaces with a water contact angle of $80.1^{\circ}, 82.7^{\circ}$ and $86.4^{\circ}$ for S-1, S-2 and S-3, respectively. This indicates that a hydrophobic DLC can be obtained by silicon treatment.

\subsection{The XPS Spectrum of Samples}

Chemical composition of the film surface was estimated by XPS analysis. The measurement within the range of $0 \mathrm{eV}$ to $1100 \mathrm{eV}$ was performed (figure not shown). Peaks of C 1s and O 1s were confirmed at $\sim 285 \mathrm{eV}$ and $\sim 531 \mathrm{eV}$, respectively. As well, in case of Si-DLC, the additional peak was observed at $\sim 100 \mathrm{eV}$ which attributed to Si2p spectrum. This result, has clarified that the DLC film is consisted mainly of Carbon and contaminated Oxygen at a ratio of $\mathrm{C}: \mathrm{O}=7: 1$, (Table 2).

Table 2: Chemical composition of undoped and silicon doped DLC films obtained by XPS measurement

\begin{tabular}{|c|c|c|c|c|}
\hline \multirow{2}{*}{ Samples } & \multicolumn{3}{|c|}{ Atom \% } & \multirow{2}{*}{ sp3/sp2 } \\
\cline { 2 - 4 } & $\mathrm{C}$ & $\mathrm{O}$ & $\mathrm{Si}$ & \\
\hline DLC & 86.7 & 13.3 & 0 & 0.55 \\
\hline S-1 & 81.9 & 13.7 & 4.5 & 0.63 \\
\hline S-2 & 76.3 & 14.1 & 9.6 & 0.67 \\
\hline S-3 & 68.5 & 14.6 & 16.7 & 0.76 \\
\hline
\end{tabular}

C 1s peak of DLC film was measured within the range of $282 \mathrm{eV}$ to $290 \mathrm{eV}$, is reported in figure 1. This spectrum can be resolved into three components. The peak at $284.6 \mathrm{eV}$ is due to $\mathrm{C}=\mathrm{C}(\mathrm{sp} 2)$. A second one observed at $285.3 \mathrm{eV}$ attributable to $\mathrm{C}-\mathrm{C}(\mathrm{sp} 3)$. The last spectrum at $287.2 \mathrm{eV}$ seems to be due to $\mathrm{CO}$ configuration. It suggests that silicon doped DLC films contained relatively high concentration of Si atoms, which caused a slight shift of the C1s spectrum toward a lower binding energy, accompanied by a broadening of the $\mathrm{C} 1 \mathrm{~s}$ peaks with FWHM of $2.5 \mathrm{eV}$, figure 1.

Si 2p spectrum was measured within the range of $97 \mathrm{eV}$ to $107 \mathrm{eV}$, is shown in figure 1 . This spectrum can be deconvoluted into three Gaussian peaks corresponding to the Si bonded to Si $(99.6 \mathrm{eV})$, Si bonded C (100.6eV) and the last one located at 102.1 due to SiO bonding. 


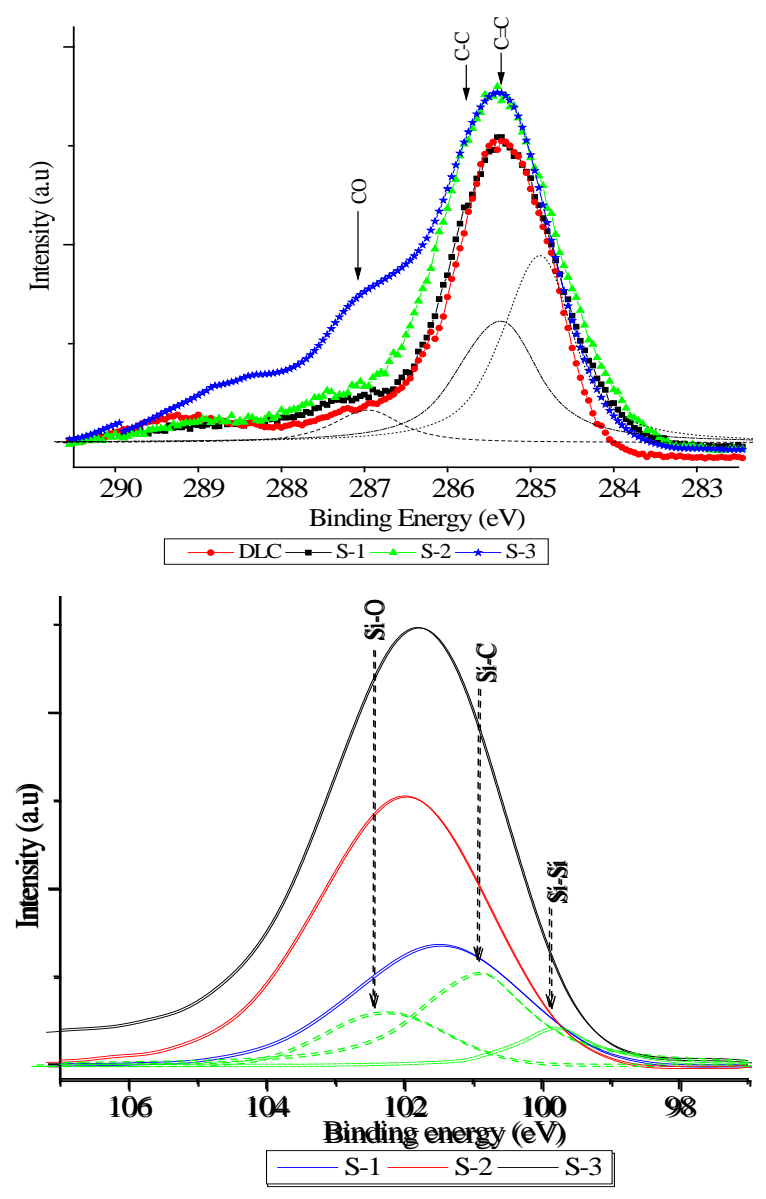

Figure 1: XPS C1s and Si 2p spectra of DLC films.

The silicon concentration in the doped films was increased from 4.5 at. $\%$ to 16.7 at. $\%$ with increasing of TMS flow rate during the film deposition from $2 \mathrm{sccm}$ to $10 \mathrm{sccm}$, whereas, carbon atoms always decrease with the increasing silicon content, (table 1 and figure 2). On the other hand, the results obtained from figure 3 show that both the $(\mathrm{O} / \mathrm{C}+\mathrm{O})$ and $(\mathrm{Si} / \mathrm{C}+\mathrm{Si})$ atomic ratios are increased with increasing of TMS flow-rate during the film deposition. 


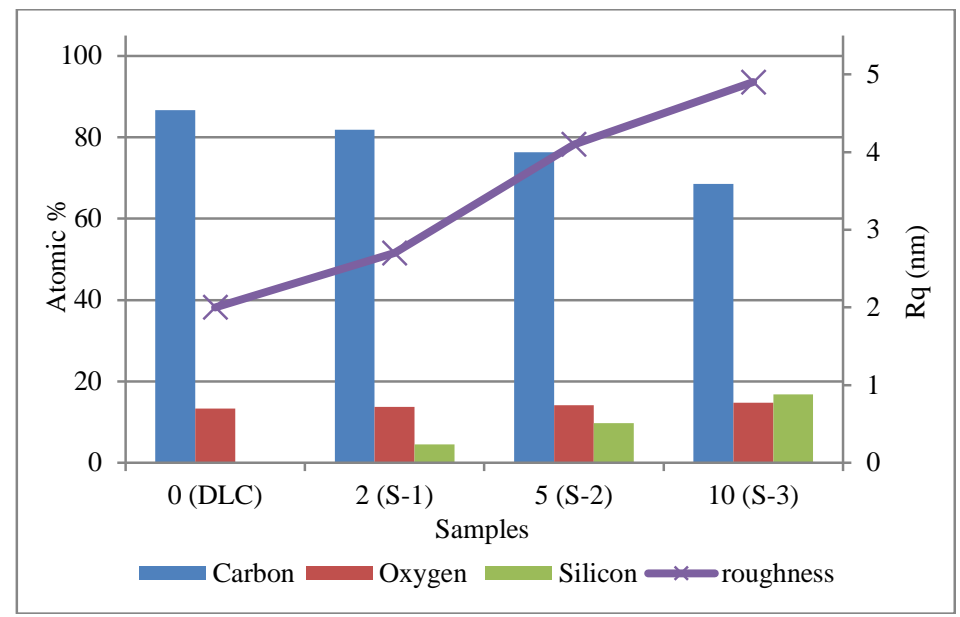

Figure 2: Carbon, Oxygen and silicon atomic concentration in the DLC films as a function of the surface roughness [rout mean square $\left(\mathrm{R}_{\mathrm{q}}\right)$ ].

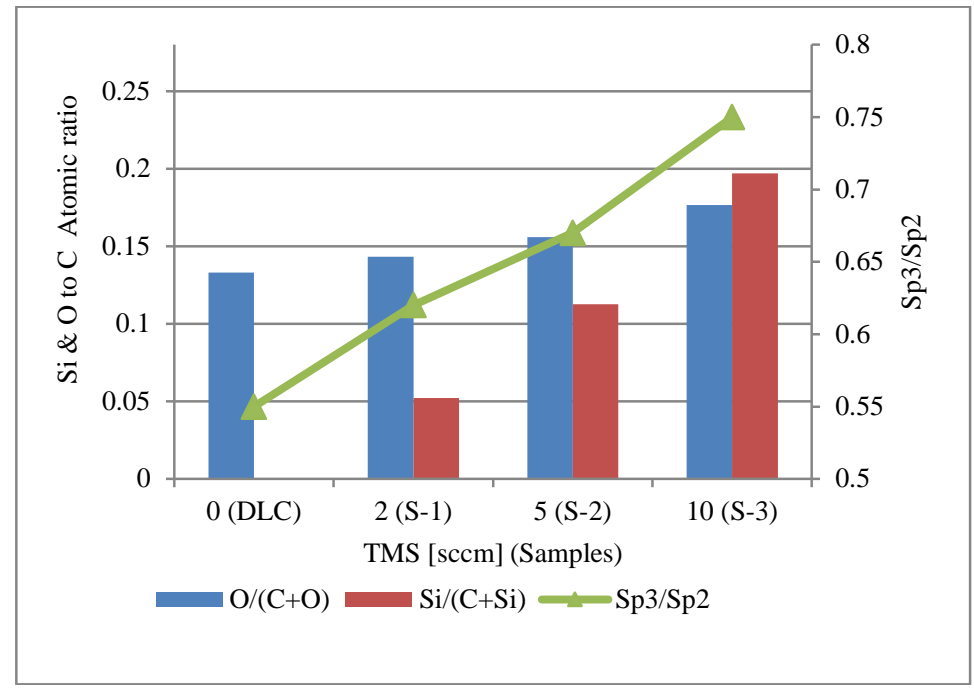

Figure 3: $\mathrm{Si} /(\mathrm{C}+\mathrm{Si})$ and $\mathrm{O} /(\mathrm{C}+\mathrm{O})$ ratios as a function of the TMS flow rate and sp3/sp2 hybridisation ratio (drive from XPS measurements)

The ratios between the sp3 to sp2 bonds in the deposited films were calculated and found to be 0.56 (for DLC). Whereas, the results showed that sp3/sp2 ratio is progressively developing with a rise of silicon concentration in the range of $0.63,0.67$ and 0.78 for S1, S-2 and S-3 samples, respectively (figure 3). Therefore, one can conclude that, since silicon forms only single bonds, the incorporated $\mathrm{Si}$ atoms substitute for sp2 bonded carbon atoms $(\mathrm{C}=\mathrm{C})$ causing a development of $\mathrm{C}-\mathrm{Si}$ bonds with the increase in the TMS flow-rate. 


\subsection{Raman Spectroscopy}

Raman spectroscopy is widely used for the investigation of sp carbon systems, as well as for a number of carbon-based systems. In addition, it can be exploited to achieve a high sensitivity in detecting small amounts of sp carbon. [19]

Raman spectra of DLC and related compounds showed a wide broad peak of carbon bands in the range of $1000-1750 \mathrm{~cm}^{-1}$. The measured spectra employed two Gaussian peaks at $1349 \mathrm{~cm}^{-1}$ and $1538 \mathrm{~cm}^{-1}$. These bands are characteristic of disordered graphite (D band) and pure graphite $\mathrm{sp}^{2}$ ( $\mathrm{G}$ band), respectively (figure 4-A). The G-peak is due to bond stretching of all pairs of $\mathrm{sp}^{2}$ configuration atoms in both rings and chains whilst the Dpeak is the shoulder of the G-peak at lower wave numbers due to the presence of the $\mathrm{sp}^{2}$ aromatic rings [20].
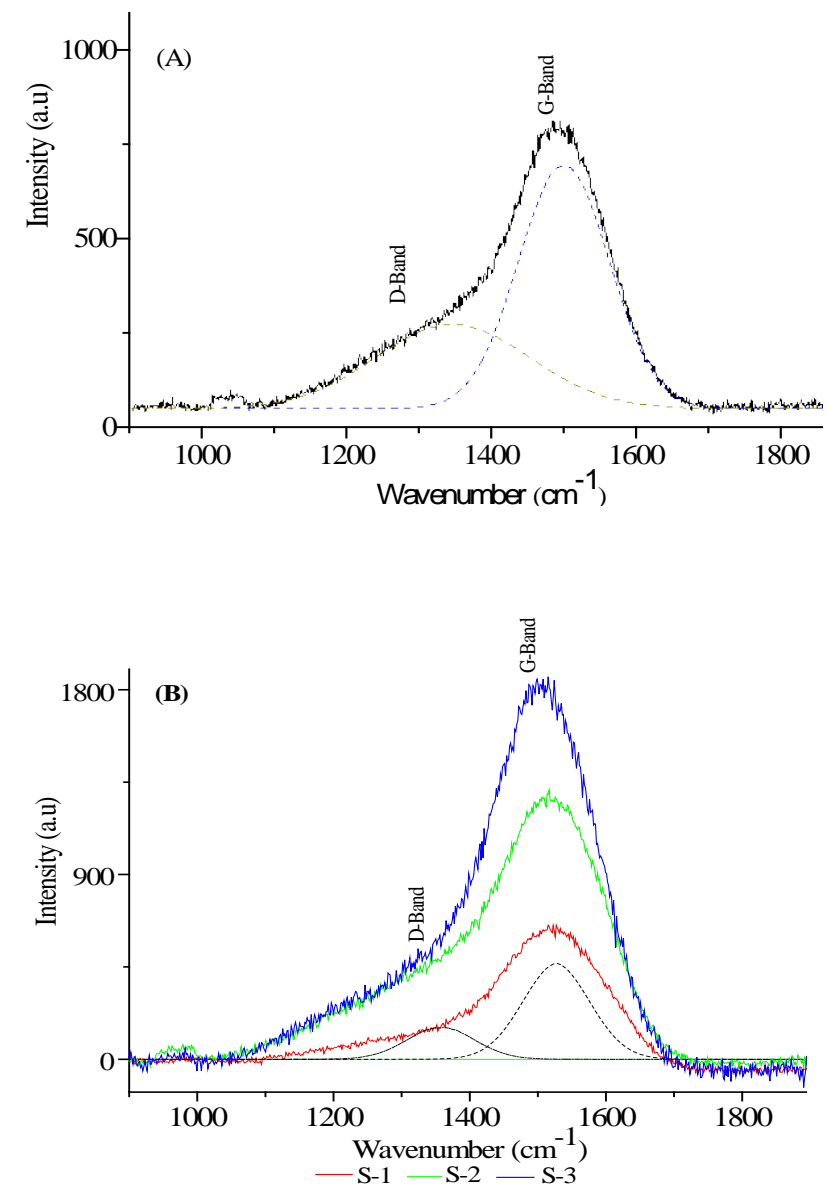

Figure 4: The Raman spectra of DLC (A) and Si-DLC (B) film samples

Whilst in the case of S-1, the typical G-band and D-band are located at $1527 \mathrm{~cm}^{-1}$ and $1344 \mathrm{~cm}^{-1}$ respectively. Furthermore, increasing the silicon concentration resulted in a red shift in the G-peak of about $12 \mathrm{~cm}^{-1}$ and $15 \mathrm{~cm}^{-1}$ in the D-peak positions (figure 4-B). This is due to the $\mathrm{sp}^{2}$ domains in Si-DLC films decreasing [12]. 
In addition, silicon has a higher atomic mass than carbon and the downshift can be attributed to the presence of Si-C bridging bonds which weaken the adjacent $\mathrm{C}-\mathrm{C}$ bonds [21].

The $\mathrm{G}$ band position is a function of the $\mathrm{sp}^{3}$ hybridisation. Following incorporation silicon into the DLC film enhance the formation of the $\mathrm{sp}^{3}$-hybridized configuration $(\sigma)$ bonding. This is equivalent to breaking the $\pi$ bonds in the $\mathrm{sp}^{2}$ hybridized aromatic ring structures causing a decrease in the intensity of D-band [22]. On the other hand when the $\mathrm{sp}^{3}$ configuration increases the $\mathrm{sp}^{2}$ cluster size will decrease and the bond order increases with a resultant Raman frequency increase [23].

Figure 5 shows the variation of $\mathrm{I}_{\mathrm{D}} / \mathrm{I}_{\mathrm{G}}$ ratio for synthesized films, which is conventionally indicative of the degree of disorder in the carbon film clusters [18]. After the initial increment, the $\mathrm{I}_{\mathrm{D}} / \mathrm{I}_{\mathrm{G}}$ value decreases linearly with increasing silicon flow rate, whereas this ratio decreased exponentially with increasing the silicon flow rate from $5 \mathrm{sccm}$ to 10 sccm. This, probably due to the change in crystallite size of sp2 hybridised bonded clusters [24]. In addition, the decrease in the $I_{D} / I_{G}$ ratio indicates an increase in the formation of atomic network and saturation of dangling bonds [25].

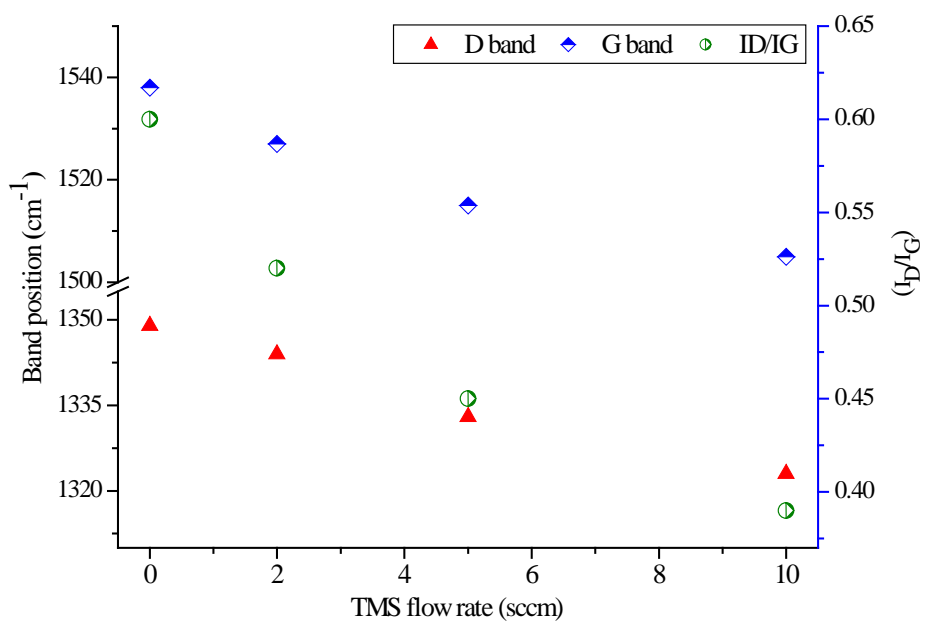

Figure 5: Raman peak position of the $\mathrm{D}$ and $\mathrm{G}$ bands with $\mathrm{I}_{\mathrm{D}} / \mathrm{I}_{\mathrm{G}}$ ratio versus TMS flow rate in doped and undoped DLC films.

These findings are in a good agreement with results of XPS measurements. Silicon atoms preferentially substitute the sp2 hybridized carbon atoms during film formation which tends to increase the C-Si contribution, while the amount of the C-C bonding (sp3) remained relatively unaltered. Since the $\mathrm{Si} / \mathrm{C}$ ratio was increased with increasing silicon flow rate, the number of sp2 cluster has been decreased. This may cause changes in the film composition 
Raman spectroscopy provides an effective method to ascertain the secondary and tertiary structural characteristics of protein. The secondary structure of protein is determined by the set of dihedral angles $(\phi, \varphi)$, which define the spatial orientation of the peptide backbone, and the presence of specific hydrogen bonds. [26]

A wide range of secondary structural markers, including $\alpha$-helix backbone $\left(930 \mathrm{~cm}^{-1}\right.$ $\left.950 \mathrm{~cm}^{-1}\right)$, amide I $\left(1600 \mathrm{~cm}^{-1}-1700 \mathrm{~cm}^{-1}\right)$, and amide III $\left(1200 \mathrm{~cm}^{-1}-1350 \mathrm{~cm}^{-1}\right)$ can be monitored. The principal geometry for the $\alpha$-helix is $\phi \sim 60^{\circ}$ and $\varphi \sim 45^{\circ}$ with hydrogen bonds from the $\mathrm{N}-\mathrm{H}$ of the fifth residue in the chain to the $\mathrm{C}=\mathrm{O}$ group on the first residue. The dihedral angles of the $\beta$-sheet are $\phi \sim 130^{\circ}$ and $\varphi \sim 120^{\circ}$, forming an extended structure. The peptide backbone in a $\beta$-turn forms a rough plane that contains the intramolecular hydrogen bond. [27,28].

Raman spectra of free and adhered HSA onto DLC and Si-DLC samples can be observed on figure 6. Significant bands assigned for the free HSA spectrum includes; the amide I band, which is sensitive to the secondary structure in protein, located at $1656 \mathrm{~cm}^{-1}$ with full width at half maximum $\left(47 \mathrm{~cm}^{-1}\right)$. The amide I modes, which involves mainly $\mathrm{C}=\mathrm{O}$ stretching, C-N stretching, $\mathrm{C} \alpha-\mathrm{C}-\mathrm{N}$ bending, and $\mathrm{N}-\mathrm{H}$ in-plane bending of $\alpha$-helical peptide groups. In contrast, the band at $\sim 1257 \mathrm{~cm}^{-1}$ is correlated to the amide III mode. The amide III band includes $\mathrm{N}-\mathrm{H}$ and $\mathrm{C}=\mathrm{O}$ in-plane bending as well as $\mathrm{C}-\mathrm{N}$ stretching and contributions from $\mathrm{C} \alpha-\mathrm{C}$ stretching modes. A band at around $849 \mathrm{~cm}^{-1}$ and $1003 \mathrm{~cm}^{-}$ 1 are attributed to the Symmetric ring breathing mode of tyrosine (tyr) and phenylalanine (phe) modes in HSA conformation, respectively. The protein backbone modes are observed in the range of $900 \mathrm{~cm}^{-1}$ to $1100 \mathrm{~cm}^{-1}$. The moderately bands observed at 1327 $\mathrm{cm}^{-1}$ and $1448 \mathrm{~cm}^{-1}$, correspond to bending vibrations of both $\mathrm{CH}_{2}$ and $\mathrm{CH}_{3}$ deformation mode [29]. The peak at $1405 \mathrm{~cm}^{-1}$ can be attributed to the symmetric stretching $\mathrm{C}=\mathrm{O}$ of ionized carboxyl groups ( $\mathrm{COO}^{-}$) of aspartic and glutamic acid, and side chain vibrations of the imidazole ring of histidine [30]. As well, a band is located at $\sim 1612 \mathrm{~cm}^{-1}$ is due to the aromatic ring mode. 


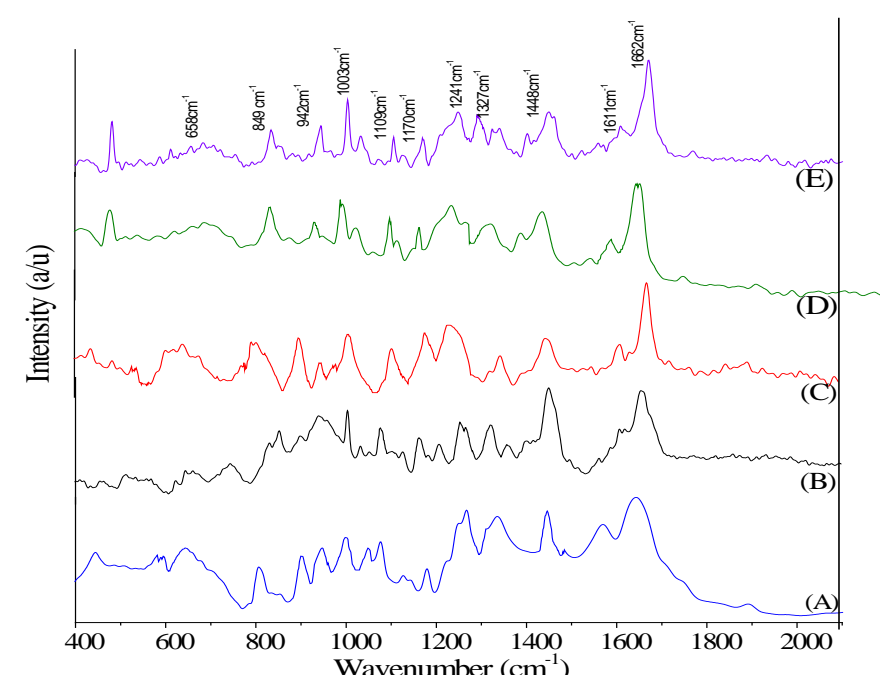

Figure 6: The Raman spectra for free (A) and adsorbed HSA on DLC (B), S-1 (C), S-2 (D) and S-3 (E).

Followed the adhesion of HSA on to DLC, the amide I band slightly shifted from 1656 $\mathrm{cm}^{-1}$ to $1664 \mathrm{~cm}^{-1}$, with FWHM wider $\left(56 \mathrm{~cm}^{-1}\right)$, and this shift well increased with addition of silicon content DLC (table 3). In contrast the band at $1612 \mathrm{~cm}^{-1}$ well shifted to near $1606 \mathrm{~cm}^{-1}$ this might be related to deprotonated of tyrosine ring during the adsorption. Whereas, the amide III envelope reflects peptide amide bonds and is observed as abroad band in the Raman spectra of adsorbed HSA. The wave-number maximum at a lower Raman shift at around (1241-1248) $\mathrm{cm}^{-1}$ is an indicative of a lower $\alpha$ - helix content in the protein's secondary structure upon adsorption onto surfaces [31].

Table 3: Characteristic Raman vibrational bands $\left(\mathrm{cm}^{-1}\right)$ of free and adsorbed HSA on DLC and Si-DLC samples

\begin{tabular}{|c|c|c|c|c|c|}
\hline \multirow{2}{*}{$\begin{array}{l}\text { Free } \\
\text { HSA }\end{array}$} & \multicolumn{4}{|c|}{ HSA adsorbed on } & \multirow{2}{*}{$\begin{array}{c}\text { Modes } \\
{[28-34]}\end{array}$} \\
\hline & DLC & S-1 & S-2 & S-3 & \\
\hline 658 & 655 & 654 & 653 & 654 & Tyr \\
\hline 849 & 853 & 852 & 853 & 853 & Tyr \\
\hline 924 & 936 & 934 & 937 & 932 & $\mathrm{C}-\mathrm{C}$ \\
\hline 1003 & 1005 & 1004 & 1004 & 1006 & phe \\
\hline 1109 & 1105 & 1102 & 1103 & 1101 & C-C, C-N, C-O \\
\hline 1170 & 1177 & 1175 & 1179 & 1176 & Tyr, phe \\
\hline 1257 & 1247 & 1248 & 1244 & 1241 & Amide III \\
\hline 1327 & 1322 & 1326 & 1324 & 1328 & $\mathrm{CH}_{2 \text { sym, def }}$ \\
\hline 1405 & 1417 & 1415 & 1416 & 1417 & $\mathrm{COO}_{\text {sym }}$ \\
\hline 1448 & 1453 & 1451 & 1452 & 1453 & $\mathrm{CH}_{3}$ def. \\
\hline 1611 & 1606 & 1605 & 1605 & 1602 & $\mathrm{ArC}=\mathrm{C}$ \\
\hline 1662 & 1668 & 1670 & 1670 & 1672 & Amide I \\
\hline
\end{tabular}

Tyr: tyrosine, phe: phenylalanine, def: deformation, sym: symmetric, $\mathrm{Ar}$ aromatic, 
Raman spectra of $\left[\mathrm{O}=\mathrm{CO}^{-}\right]$stretching mode appeared at $\sim 1417 \mathrm{~cm}^{-1}$, these blue shift might be related to the chemical reaction of side chain carboxylic group with the surface [32]. The results agree with our previous experiments, suggested that the adsorption of glycine on to Si-DLC accrued through carboxylic acid group [12].

Curve fitting of the amide I band was performed to indicate the secondary structural compositions of HSA using Gaussian model, (figure 7). The bands of free HSA were located at 1614, 1634, $1654 \mathrm{~cm}^{-1}$ and $1669 \mathrm{~cm}^{-1}$ which is related to aromatic ring vibration, random coil, $\alpha$-helix and $\beta$-sheet components, respectively, whilst the bands between $1680-1690 \mathrm{~cm}^{-1}$ region reflects the contribution of $\beta$-turn [33].
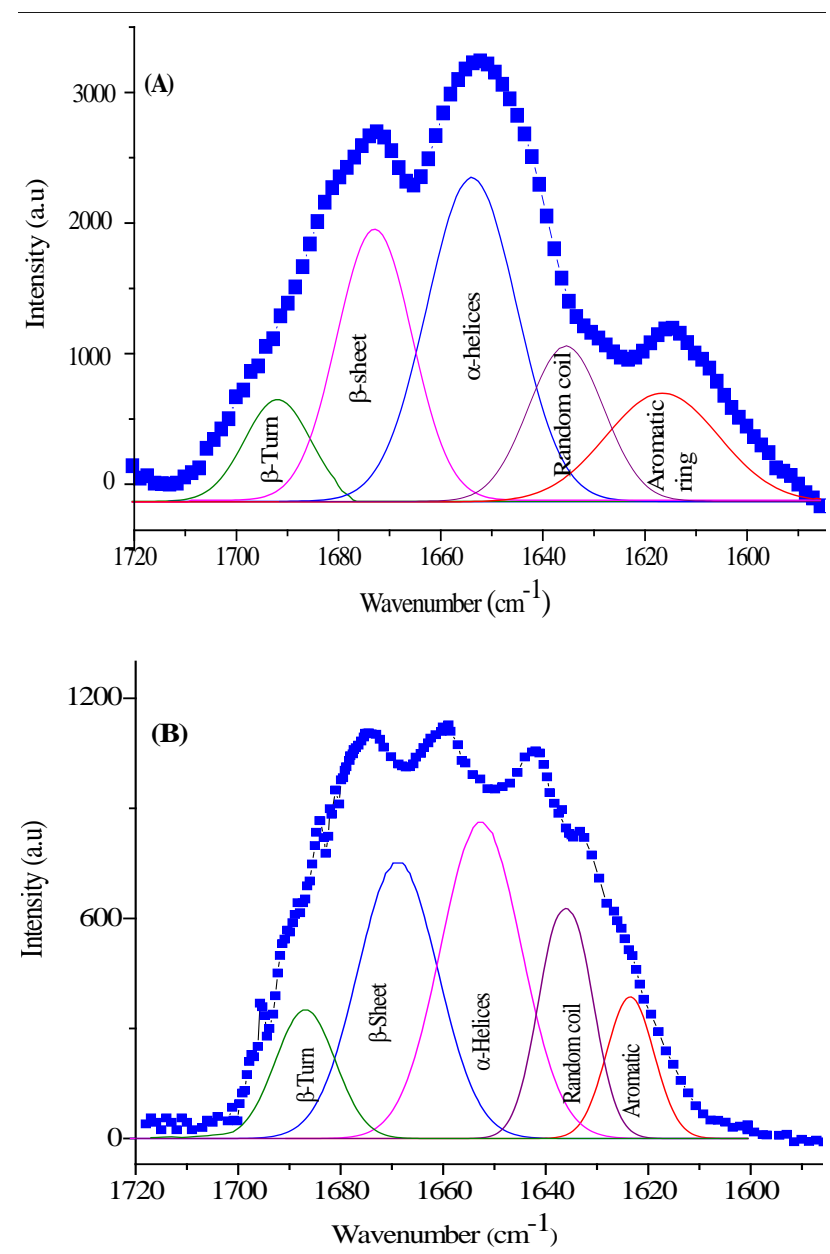


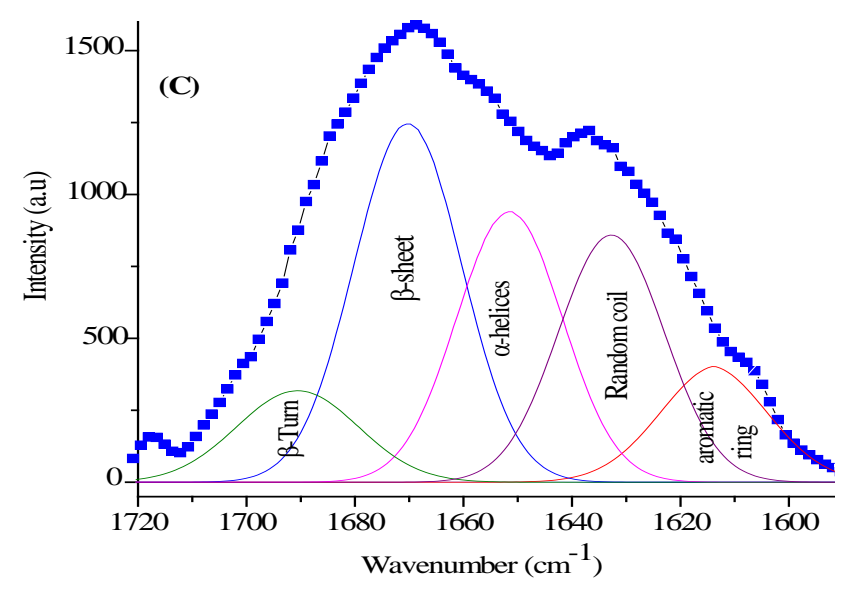

Figure 7: Curve fitting of the Amide I band vibration mode of free HSA (A) and adsorbed on DLC (B) and on S-3 (C) surfaces.

Based on the analysis data, the free HSA protein consisted of 53.3\% $\alpha$-helix $\left(1653 \mathrm{~cm}^{-1}\right)$, 11.3\% random coil $\left(1635 \mathrm{~cm}^{-1}\right), 23.1 \% \beta$-sheet $\left(1669 \mathrm{~cm}^{-1}\right)$ and $12.2 \% \beta$-tum $\left(1687 \mathrm{~cm}^{-}\right.$ ${ }^{1}$ ), this finding is consistent with our previous research that HSA contained major $55 \%$ of $\alpha$-helix and $45 \% \beta$-structure in $\mathrm{pH} 7.4$ buffer solution $[34,35]$.

For the HSA adhered onto the samples, the amide I band fit of HSA showed a decrease in the $\alpha$-helix band intensity to (46\%) with a slight increase in both $\beta$-sheet and random coil conformations (table 4). This indicated the presence of conformational changes of HSA during the adsorption. In case of adsorbed HSA on Si-DLC surfaces, the deconvoluted band at $\sim 1634 \mathrm{~cm}^{-1}$ can be assigned to the random conformation which increases relative to the band at $\sim 1653 \mathrm{~cm}^{-1}$ ( $\alpha$-helix region) with increasing silicon doping of DLC. As well, an increase from $26 \%$ to $32 \% \beta$-sheet is observed with increasing of silicon concentration in a film to 16.7 at. \%. This finding corroborates the ideas of Wang et al, who suggested that, the proteins will tend to adsorb on the hydrophobic surface by hydrophobic patches of residues present in the protein's amphiphilic structure. Protein would unfold and spread its hydrophobic core over the surface owing to the thermodynamic driving force to reduce the net hydrophobic surface area of the system exposed to the solvent [36]. While the hydrophilic amino acid moieties, which are not in a close proximity to the adsorbing hydrophobic domains, are allowed to dangle to the exterior and interact with the aqueous environment. [37]. 
Table 4: Assignment of amide I band positions to secondary structures of HSA before and after adsorption on DLC and Si-DLC

\begin{tabular}{|c|c|c|c|c|c|c|c|c|c|c|}
\hline \multirow{2}{*}{ Structure } & \multicolumn{2}{|c|}{ Free HSA } & \multicolumn{9}{|c|}{ HSA adsorbed on } \\
\cline { 2 - 11 } & $\begin{array}{c}v \\
\mathrm{~cm}^{-1}\end{array}$ & $\begin{array}{c}\text { Band } \\
\%\end{array}$ & $\begin{array}{c}v \\
\mathrm{~cm}^{-1}\end{array}$ & $\begin{array}{c}\text { Band } \\
\%\end{array}$ & $\begin{array}{c}v \\
\mathrm{~cm}^{-1}\end{array}$ & $\begin{array}{c}\text { Band } \\
\%\end{array}$ & $\begin{array}{c}v \\
\mathrm{~cm}^{-1}\end{array}$ & $\begin{array}{c}\text { Band } \\
\%\end{array}$ & $\begin{array}{c}v \\
\mathrm{~cm}^{-1}\end{array}$ & $\begin{array}{c}\text { Band } \\
\%\end{array}$ \\
\hline $\begin{array}{c}\text { random } \\
\text { coil }\end{array}$ & 1633 & 11.3 & 1634 & 13.7 & 1634 & 14.8 & 1633 & 15.9 & 1634 & 17.6 \\
\hline$\alpha$-helix & 1653 & 53.3 & 1652 & 46.2 & 1652 & 42.4 & 1654 & 41.1 & 1653 & 39.3 \\
\hline$\beta$-sheet & 1670 & 23.1 & 1669 & 26.9 & 1670 & 28.6 & 1670 & 30.2 & 1668 & 31.8 \\
\hline$\beta$-turn & 1687 & 11.7 & 1685 & 12.8 & 1686 & 13.5 & 1687 & 13.4 & 1688 & 13.7 \\
\hline
\end{tabular}

(v): Raman shift band $\left(\mathrm{cm}^{-1}\right)$.

The results inferred that silicon doping of DLC tends to increase of the $\beta$-sheet peak area with reducing $\alpha$-helix content. Comparing these results with native protein indicates that the secondary structure of protein has been partially disordered due to the binding of HSA to the surfaces.

These results are consistent with our previous analysis, which was obtained from ellipsometry spectroscopy [38], suggested that the surface of samples undergo a significant reduction in $\cos \Delta$, following the adhesion of HSA and this gap increases with increasing the silicon content in the surface of the samples. This result is in agreement with Benesch et al who reported that reduction in the $(\Delta)$ value corresponds with the increasing surface coverage of HSA layers [39].

The finding is correlated with Naksnishi et al, who found that the proteins adsorb on hydrophobic surfaces, which leads to a structural change upon adsorption onto the surface [40]. This is compelling evidence that the presence of silicon enhances the adsorption of HSA onto the surface of DLC; this might tend to reduce the adsorption of fibrinogen. This indicates that the adsorption onto the coated DLC results in a change in the protein conformation from $\alpha$-helix to $\beta$-sheet.

\subsection{Atomic force microscopy (AFM) analysis:}

The roughness of the film surface is generally characterized by the rms (root mean square, $\mathrm{R}_{\mathrm{q}}$ ) value. The three-dimensional topography of both doped and undoped films is displayed in figure 8. The undoped DLC thin film showed a smooth and flat surface with the root mean square value $\left(\mathrm{R}_{\mathrm{q}}\right)$ roughness around $1.97 \mathrm{~nm}$. This finding is similar to those obtained in our previous investigation [41]. 


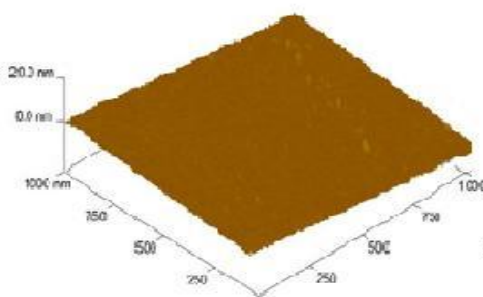

A
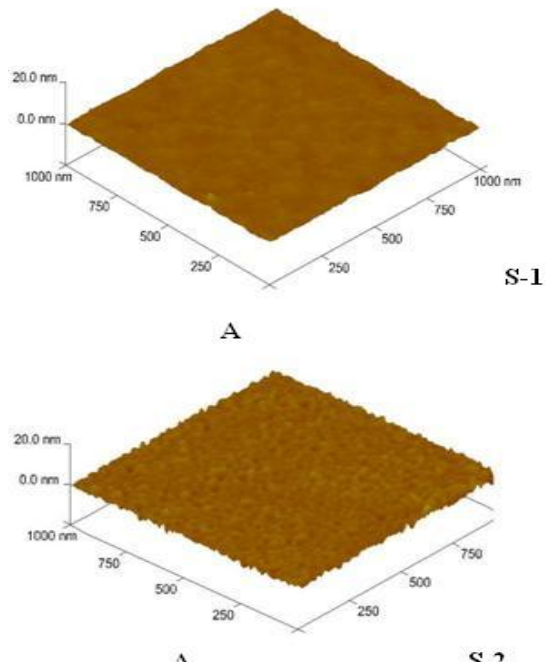

$\mathrm{S}-2$

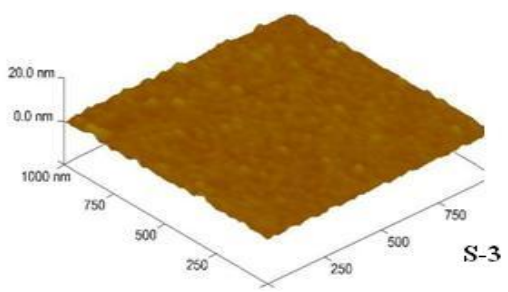

A

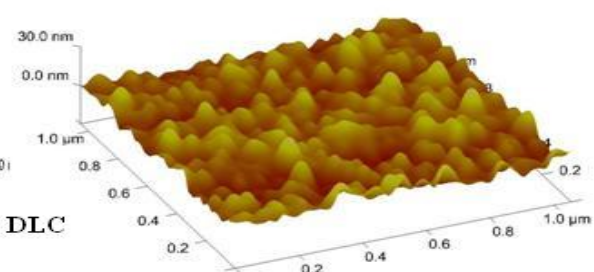

$\mathbf{B}$
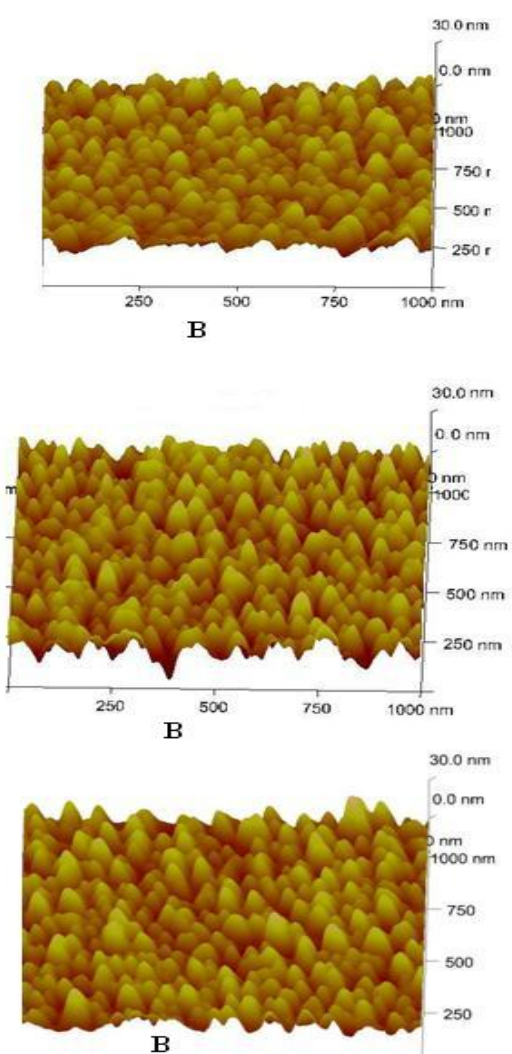

Figure 8: Topographical AFM images of DLC and Si-DLC surfaces before (A) and after (B) protein adhesion.

In the case of Si-DLC samples the morphological peaks of films are quite sharp compared to the peaks in DLC film. The root-mean-squared roughness (rms or $\mathrm{R}_{\mathrm{q}}$ ) of the samples versus the Si concentration is summarized in table 5 . The $\mathrm{R}_{\mathrm{q}}$ value of samples was 2.7 $\mathrm{nm}, 4.1 \mathrm{~nm}$ and $4.9 \mathrm{~nm}$ for S-1, S-2 and S-3, respectively. 
Table 5: The various morphological parameters of DLC and Si-DLC thin films before and after adsorption of HSA

\begin{tabular}{|c|c|c|c|c|c|c|c|c|}
\hline \multirow{2}{*}{$\begin{array}{c}\text { Paramete } \\
\text { rs } \\
(\mathrm{nm}) \\
\text { scale }\end{array}$} & \multicolumn{2}{|c|}{ DLC } & \multicolumn{2}{|c|}{ S-1 } & \multicolumn{2}{c|}{ S-2 } & \multicolumn{2}{c|}{ S-3 } \\
\cline { 2 - 9 } & Before & After & Before & After & Before & After & Before & After \\
\hline $\begin{array}{c}\text { Root } \\
\text { mean } \\
\text { square } \\
\text { [rms] } \\
\left(\mathrm{R}_{\mathrm{q}}\right)\end{array}$ & $1.97 \pm 0.13$ & $6.16 \pm 0.54$ & $2.74 \pm 0.15$ & $6.24 \pm 0.62$ & $4.14 \pm 0.18$ & $6.92 \pm 0.51$ & $4.93 \pm 0.2$ & $7.20 \pm 0.64$ \\
\hline $\begin{array}{c}\text { Average } \\
\text { height }\end{array}$ & $3.48 \pm 1.3$ & $18.46 \pm 1.9$ & $4.25 \pm 1.5$ & $19.17 \pm 2.0$ & $5.9 \pm 1.5$ & $22.32 \pm 2.2$ & $7.6 \pm 0.9$ & $25.42 \pm 2.1$ \\
\hline $\begin{array}{c}\text { Maximu } \\
\text { m height }\end{array}$ & $\begin{array}{c}10.25 \pm 0.7 \\
6\end{array}$ & $\begin{array}{c}27.53 \pm 1.8 \\
2\end{array}$ & $\begin{array}{c}11.63 \pm 0.5 \\
8\end{array}$ & $\begin{array}{c}28.41 \pm 1.6 \\
4\end{array}$ & $\begin{array}{c}14.12 \pm 1.1 \\
3\end{array}$ & $\begin{array}{c}30.72 \pm 2.3 \\
4\end{array}$ & $\begin{array}{c}18.32 \pm 1.8 \\
7\end{array}$ & $\begin{array}{c}34.68 \pm 3.2 \\
1\end{array}$ \\
\hline $\begin{array}{c}\text { Roughnes } \\
\mathrm{s}\left(\mathrm{R}_{\mathrm{a}}\right)\end{array}$ & $0.72 \pm 0.08$ & $1.8 \pm 0.11$ & $1.18 \pm 0.17$ & $1.88 \pm 0.2$ & $1.63 \pm 0.15$ & $1.96 \pm 0.21$ & $2.18 \pm 0.18$ & $2.50 \pm 0.16$ \\
\hline
\end{tabular}

$(\mathrm{nm})$ : is nanometre, rms or $\left(\mathrm{R}_{\mathrm{q}}\right)$ : roughness is based on a least square calculated with the best fit of the height points. $\left(R_{a}\right)$ : is obtained by a logarithm which measures the average deviation between the peaks and values from the mean line of the surfaces. $( \pm$ ): represent the values calculated standard deviation ( $\mathrm{n}=3$ samples).

Figure 2 shows the surface roughness of the films as a function of the atomic concentration in the film composition. As one can see, the surface roughness increases with increasing the silicon atomic concentration in the Si-DLC films. This may return to the bonding configuration. When DLC is doped with Si there is an increase in the hydrogen concentration and these phenomena tend to enhance the proportion of sigma bonds which increase the $\mathrm{R}_{\mathrm{q}}$ values [42]. These results are consistent with other research suggesting that silicon content DLC tends to increase the $R_{q}$ value $[43,44]$.

In order to determine the change in the surface topography, AFM was used to investigate and visualize conformation and morphologic characteristics resulting from adsorption of HSA onto doped and undoped DLC films (Figure 8). The results show that HSA adsorbed on both doped and undoped surfaces as a grain shape with an average height of 18-25 nm. As seen from figure 8 and table 5 , a significant change in the $R_{q}$ values was observed following HSA adsorption, i.e. for DLC, the $\mathrm{R}_{\mathrm{q}}$ changed to $6.1 \mathrm{~nm}$, and in case of the doped samples, the $\mathrm{R}_{\mathrm{q}}$ value increased to 6.2, 6.9 and $7.2 \mathrm{~nm}$ for $\mathrm{S}-1, \mathrm{~S}-2$ and $\mathrm{S}-3$, respectively. The results showed good agreement with those obtained by Buijs et al, who concluded that hydrophobic surface significantly contribute to strong protein/substrate interactions, and suggested that proteins undergo structural rearrangements and spread upon adsorption [45].

One can observe that the surface roughness of adsorbed HSA increased with increasing of surface roughness of samples. This might return to existence of silicon and hydrogen in the DLC films that are more electropositive than carbon will result in the formation a 
surface dipole with an external positively charged side on the silicon doped DLC film. This phenomenon is believed to be the responsible for anchoring the negatively charged of the HSA molecules.

As mentioned above, silicon incorporated DLC tended to increase the water contact angle (more hydrophobic). This could play a role in the increase of HSA adsorption on the SiDLC film surface; because a more hydrophobic surface reduces its interaction with water molecules allowing more direct contact with the protein, rather than an interaction mediated by a water layer and this will increase the adsorption layer. These results are in correlation with Ogwu et al, who suggested that increasing the surface hydrophobicity tends to promote human endothelial cell growth and adhesion on the films [46].

On the other hand, adsorption from solutions of protein takes place in two different processes. The first process is fast and results in the direct adsorption of the protein molecules that attach to the surface without changing their conformation and then move laterally into a hexagonal close-packed (HCP) configuration. The second step which is slower than the first step; the proteins adsorb randomly and irreversibly at a site on the surface and the thickness of the layer gradually increases with the adsorbed amount due to the conformational change taking place in the direction normal to the surface $[40,47]$.

\section{Conclusions}

DLC and Si doped DLC have been synthesised and showed that silicon content in the DLC tends to decrease the $\mathrm{I}_{\mathrm{D}} / \mathrm{I}_{\mathrm{G}}$ with an increase in the surface roughness behaviour of samples. It is found that the silicon doping may improve the surface morphology and film thicknesses of DLC sample.

The interactions between adsorbed HSA molecules and the surface of samples played an essential role in influencing these results. Followed the adhesion of HSA onto the samples, the secondary structure of the adsorbed protein has changed from $\alpha$-helices to the $\beta$-sheet mode with slight increase of the random coil feature.

The results from the AFM, found that the $\left(R_{q}\right)$ values increase with increasing silicon content in the DLC samples. Since the Protein adsorption behaviour on the surfaces of biomedical materials depends on the surface properties, such as material chemistry and morphology, the AFM analysis showed that the surface roughness of samples

significantly increased following exposure to protein. The results suggested that a multilayer of HSA covered the doped and undoped DLC samples, and this was improved 
by the addition of silicon content. When the adsorption of HSA increases it tends to reduce fibrinogen adsorption and lowers platelet adhesion. This might improve the biocompatibility of the implant; however, further studies are required to obtain a better understanding of protein adsorption in vivo.

\section{References}

1- R. A. Latour, Molecular simulation of protein-surface interactions: Benefits, problems, solutions, and future directions (Review) Biointerphases. 3:3 (2008), FC2-FC12.

2- S. Lousinian, S. Logothetidis, A. Laskarakis, M. Gioti, Haemo-compatibility of amorphous carbon thin films, optical properties and adsorption mechanisms of blood plasma proteins, Biomolecular Engineering 24 (2007) 107-112.

3- S. Kumar Jaganathan, E. Supriyanto, S. Murugesan, A. Balaji, and M. K. Asokan, Biomaterials in Cardiovascular Research: Applications and Clinical Implications, BioMed Research International, (2014), Article ID 459465, 11 pages. doi:10.1155/2014/459465.

4- H. W. Choi, R. H. Dauskardt, S.C. Lee, K. R. Lee, K. H. Oh, Characteristic of silver doped DLC films on surface properties and protein adsorption, Diamond \& Related Materials 17 (2008) 252-257.

5- A. Alanazi, C. Nojiri, T. Kido, T. Noguchi, Y. Ohgoe, T. Matsuda, K. Hirakuri, A. Funakubo, K. Sakai, Y. Fukui, Engineering Analysis of Diamond-Like Carbon Coated Polymeric Materials for Biomedical Applications Artificial Organs 24:8 (2000) 624-627.

6- D. Grimanelis, S. Yang, O. Bohme, E. Roman, A. Alberdi, D.G. Teer, J.M. Albella, Carbon based coatings for high temperature cutting tool applications, Diamond and Related Materials 11 (2002) 176-184.

7- H.W. Choi, R.H. Dauskardt, S.C. Lee, K.R. Lee, K.H. Oh, Characteristic of silver doped DLC films on surface properties and protein adsorption, Diamond \& Related Materials 17 (2008) 252-257.

8- J. I. Onate, M. Comin, I. Braceras, A. Garcia, J.L. Viviente, M. Brizucla, N. Garagorri, J.L. Peris, J.I. Alava, Wear reduction effect on ultra-high-molecularweight polyethylene by application of hard coatings and ion implantation on cobalt chromium alloy, as measured in a knee wear simulation machine, Surface Coatings Technology 142-144 (2001)1056-1062.

9- S. Jahanmir, A.Z. Hunsberger, H. Heshmat, Load capacity and durability of HDLC coated hydrodynamic thrust bearings, Load Capacity and Durability of HDLC Coated Hydrodynamic Thrust Bearings, Journal of Tribology 133 (2011) 031301-31311.

10- M. H. Ahmed, J. A. Byrne, Effect of surface structure and wettability of DLC and N-DLC thin films on adsorption of glycine, Applied Surface Science, 258 (2012) 5166- 5174. 
11- M. H. Ahmed, J. A. Byrne, J. McLaughlin, Evaluation of glycine adsorption on diamond like carbon (DLC) and fluorinated DLC deposited by plasma-enhanced chemical vapour deposition (PECVD), Surface \& Coatings Technology 209 (2012) 8-14.

12- M. H. Ahmed, J. A. Byrne, J.A.D. McLaughlin, A. Elhissi, W. Ahmed, Comparison between FTIR and XPS characterization of amino acid glycine adsorption onto diamond-like carbon (DLC) and silicon doped DLC, Applied Surface Science 273 (2013) 507- 514.

13- W-C. Feng, C-H. Wang, H-C. Cheng, S-Y. Chiou, C-S. Chen and K-L. Ou, Enhancement of hemocompatibility on titanium implant with titanium-doped diamond-like carbon film evaluated by cellular reactions using bone marrow cell cultures in vitro, J. Vac. Sci. Technol. B, 27:32 (2009) 1559-1565.

14- S-F. Ou, C-S Chen, H. Hosseinkhani, C-H. Yu, Y-D. Shen, K-L. Ou, Surface properties of nanostructural silicon-doped carbon films for biomedical applications, Int. J. of Nanotechnology 10: (10-11) (2013) 945 - 958.

15- N. Moolsradoo, S. Abe and S. Watanabe, Thermal Stability and Tribological Performance of DLC-Si-O Films, Advances in Materials Science and Engineering, Article ID 483437 (2011) 7 pages, 2011.doi:10.1155/2011/483437.

16- R. K. Roy, H. W. Choi, J. W. Yi, M. W. Moon, K. R. Lee, D. K. Han, J. H. Shin, A. Kamijo, T. Hasebe, Hemocompatibility of surface-modified, siliconincorporated, diamond-like carbon films Acta Biomater. 5 (2009) 249-256.

17- M. H. Ahmed, J. A. Byrne, J. McLaughlin, W. Ahmed, Study of Human Serum Albumin Adsorption and Conformational Change on DLC and Silicon Doped DLC Using XPS and FTIR Spectroscopy, Journal of Biomaterials and Nanobiotechnology, 4 (2013) 194-203.

18- B. Zhang, J. Li, J. Sun, Solid solution of $\mathrm{Al}$ and $\mathrm{N}$ in nano-sized $\alpha$-SiC powder by carbothermal reduction of the xerogels of $\mathrm{SiO}_{2}-\mathrm{Al}_{2} \mathrm{O}_{3}$, Materials Letters $\mathbf{5 1}$ (2001) 219-224.

19- A Lucotti, C. S Casari, M Tommasini, A Li Bassi, D Fazzi, V Russo sp Carbon chain interaction with silver nanoparticles probed by Surface Enhanced Raman Scattering Chemical Physics Letters 478:1 (2009), 45-50

20- F. Klauser, D. S-Nethl, R. Kaindl, E. Bertel, N. Memme, Raman Studies of Nano- and Ultra-nanocrystalline Diamond Films Grown by Hot-Filament CVD, Chemical Vapour Deposition 16:4-6 (2010) 127-135.

21- A. Bendavid, P. J. Martin, C. Comte, E.W. Preston, A. J. Haq, F. S. M. Ismail, R. K. Singh, The Mechanical And Biocompatibility Properties of DLCSi Films Prepared by Pulsed DC Plasma Activated Chemical Vapor Deposition, Diamond \& Related Materials 16 (2007) 1616-1622.

22-S. E. Ong, S. Zhang, H. Du, H. C. Too, K. N. Aung, Influence of silicon concentration on the haemocompatibility of amorphous carbon, Biomaterials $\mathbf{2 8}$ (2007) 4033-4038.

23- F-X. Liu, Z-L. Wang, Thickness dependence of the structure of diamondlike carbon Films by Raman spectroscopy, Surface \& Coatings Technology 203 (2009) 1829-1832. 
24- R. Hatada, S. Flege, K. Baba, W. Ensinger, H.-J. Kleebe, I. Sethmann, and S. Lauterbach, Temperature dependent properties of silicon containing diamond like carbon films prepared by plasma source ion implantation, Journal of Applied Physics 107: 083307 (2010) doi:10.1063/1.3394002.

25- N. Woehrl, O. Ochedowski, S. Gottlieb, K. Shibasaki, and S. Schulz, Plasmaenhanced chemical vapour deposition of graphene on copper substrates, AIP Advances 4, 047128 (2014); doi: 10.1063/1.4873157

26- J. T. Pelton and L. R. McLean, Spectroscopic Methods for Analysis of Protein Secondary Structure, Analytical Biochemistry 277 (2000) 167-176

27- S. Wang and W-M Zheng, Fast Multiple Alignment of Protein Structures Using Conformational Letter Blocks, The Open Bioinformatics Journal, 3 (2009) 6983.

28- M. A.H. Capelle, R. Gurny, T. Arvinte, High throughput screening of protein formulation stability: Practical considerations. European Journal of Pharmaceutics and Biopharmaceutics 65 (2007) 131-148.

29- E. C. Y. Li-Chan, The applications of Raman spectroscopy in food science, Trends in Food Science \& Technology 7:11 (1996) 361-370.

30- C. C. Orfanidou, S. J. Hamudrakas, G. D. E. Chryssikos, I. Kamitsos, S. E. Wellman, S. T. Case, Spectroscopic studies of Manduca sexta and Sesamia nonagrioides chorion protein structure, International Journal of Biological Macromolecules 17:2 (1995) 93-98.

31- Z. Chi, X.G. Chen, J.S. Holtz, S.A. Asher, UV resonance Raman-selective amide vibrational enhancement: quantitative methodology for determining protein secondary structure. Biochemistry, 37:9 (1998) 2854-64.

32- H. I. Lee, M. S. Kim and S. W. Suh, Raman spectroscopy of L-phenylalanine, Ltyrosine, and their peptides adsorbed on silver surface, Bull. Korean Chem. Soc. 9:4 (1988) 218-223.

33- A. Synytsya, P. Alexa, J. de Boer, M. Loewe, M. Moosburger, M. Wurkner, K. Volka, Raman spectroscopic study of serum albumins: an effect of proton- and $\gamma$-irradiation , Journal of Raman Spectroscopy 38 (2007) 1646-1655.

34- M. H. Ahmed, T. E. Keyes, J. A. Byrne, C. W. Blackledge, J. W. Hamilton, Adsorption and photocatalytic degradation of human serum albumin on $\mathrm{TiO}_{2}$ and Ag-TiO 2 films, Journal of Photochemistry and Photobiology A: Chemistry 222 (2011) 123- 131.

35- C. Tiede, A. A. S.Tang, S. E.Deacon, U.Mandal, J. E.Nettleship, R. L.Owen, S. E.George, D. J.Harrison, R. J.Owens, D. C.Tomlinson and M. J. McPherson, Adhiron: a stable and versatile peptide display scaffold for molecular recognition applications, Protein Eng Des Sel. 27:5 (2014) 145-55

36- K. Wang, C. Zhou, Y. Hong and X. Zhang, A review of protein adsorption on bioceramics , interface focus doi:10.1098/rsfs.2012.0012.

37- K. K. Goli, O. J. Rojas, A. E. Ozcam and J. Genzer,Generation of Functional Coatings on Hydrophobic Surfaces through Deposition of Denatured Proteins Followed by Grafting from Polymerization Biomacromolecules, 13:5 (2012) 1371-1382. 
38- M. H. Ahmed, J. A. Byrne, J. McLaughlin, Kinetics and Thermodynamics of Human Serum Albumin Adsorption on Silicon Doped Diamond Like Carbon, Materials Chemistry and Physics,154 (2015) 84-93.

39- J. Benesch, A. Askendal, and P. Tengvall, The Determination of Thickness and Surface Mass Density of Mesothick Immunoprecipitate Layers by Null Ellipsometry and Protein 125Iodine Labeling, Journal of Colloid and Interface Science 249 (2002) 84-90

40- K. Naksnishi, T. Sakiyama and K. Imamura, Review on the Adsorption of Proteins on Solid Surfaces, a Common but Very Complicated Phenomenon, Journal of Bioscience and Bioengineering, 91:3 (2001) 233-244.

41- M. Ahmed, A. J. Byrne, J. McLaughlin, A. Elhissi, D. A. Phoenix and W. Ahmed, Vibrational and AFM studies of adsorption of glycine on DLC and silicon-doped DLC, J Mater Sci 47 (2012) 1729-1736.

42- X-M. He,K. C. Walter and M. Nastasi, Plasma-immersion ion-processed borondoped diamond-like carbon films, J. Phys.: Condens. Matter 12 (2000) L183L189

43- J. Wang, J. Pu, G. Zhang, L. Wang, Tailoring the structure and property of silicon-doped diamond-like carbon films by controlling the silicon content, Surface \& Coatings Technology 235 (2013) 326-332.

44- K-H. Era and M-Gi. So, Thermal stability of reactive sputtered silicon-doped diamond-like carbon films, Journal of Ceramic Processing Research. 14:1 (2013) 134-138.

45- J. Buijs and V. Hlady, Adsorption kinetics, conformation, and mobility of growth hormone and lysozyme on solid surfaces, studied with TIRF. Journal of colloid and interface science, 190 (1997) 171-181.

46- A. Ogwu, T. I. T. Okpalugo, N. Ali, P. D. Maguire, J. A. D. McLaughlin, Endothelial Cell Growth on Silicon Modified Hydrogenated Amorphous Carbon Thin Films, J Biomed Mater Res Part B: Appl Biomater 85B (2008) 105-113.

47- C. Mathe, S. Devineau, J-C. Aude, G. Lagniel, S. Chedin, V. Legros, M-H. Mathon, J-P. Renault, S. Pin, Y. Boulard, J. Labarre, Structural Determinants for Protein adsorption/nonadsorption to Silica Surface, PLOS ONE 8:11 (2014) e81346. doi:10.1371/journal.pone.0081346 